\title{
CONHECIMENTO SOBRE PLANTAS MEDICINAIS DE ESTUDANTES DE ENSINO FUNDAMENTAL DE DUAS ESCOLAS
}

Ketlin Fernanda Rodrigues ${ }^{1}$

Fernanda Bruxel ${ }^{2}$

Sabrina Grando Cordeiro ${ }^{3}$

Lucélia Hoehne ${ }^{4}$

Elisete Maria de Freitas ${ }^{5}$

Resumo: O objetivo do estudo foi identificar o nível de conhecimento sobre plantas medicinais dos estudantes do sétimo ano do Ensino Fundamental de duas escolas, uma pública e outra particular, e avaliar a importância da realização de intervenções com atividades teórica e prática sobre o tema. Foram aplicados dois questionários em cada escola, com questões sobre plantas medicinais, um antes (Questionário 1) e outro (Questionário 2) após a realização de uma intervenção composta por uma parte prática e outra teórica. A intervenção atribuiu aos alunos novas percepções sobre utilização da biodiversidade e sobre a necessidade da sua preservação, favorecendo a formação de cidadãos ecologicamente mais conscientes.

Palavras-chave: Atividades Práticas; Biodiversidade; Conhecimento Tradicional; Educação Ambiental; Espécies Medicinais.

1 Universidade do Vale do Taquari. E-mail: ketyfernanda @hotmail.com

2 Universidade do Vale do Taquari. E-mail: fbruxel1@universo.univates.br

${ }_{3}^{3}$ Universidade do Vale do Taquari. E-mail: sabrina.cordeiro@universo.univates.br

4 Universidade do Vale do Taquari. E-mail: Iuceliah@univates.br

${ }^{5}$ Universidade do Vale do Taquari. E-mail: elicauf@univates.br

Revbea, São Paulo, V. 14, № 4: 204-218, 2019. 


\section{Introdução}

O uso das plantas está diretamente relacionado à cura de doenças em escala mundial e em todos os períodos históricos da humanidade. A sua utilização provavelmente surgiu no momento em que o homem primitivo precisava suprir suas necessidades básicas e, como eram dependentes da natureza para a sobrevivência, introduziram o consumo de plantas para o tratamento de doenças a partir de observações das suas características e do comportamento ou reação provocada nos animais após o seu consumo e ainda, após tentativas de uso (ALMEIDA, 2011).

De acordo com Monteiro e Brandelli (2017), as primeiras descrições do uso de plantas para a cura de doenças datam de 2.600 a. C. Por muito tempo, as plantas medicinais e seus compostos foram os principais recursos para o tratamento de doenças. Porém, a partir da Idade Contemporânea, mais precisamente no século XIX, com o avanço científico na área da química, mais informações sobre os compostos bioativos das plantas passaram a ser obtidas, promovendo maior progresso na utilização de plantas para a elaboração de medicamentos. A partir desses avanços, no final do século XIX e início do século XX surgiu a maioria das indústrias farmacêuticas mundiais (WONGTSCHOWSKI, 2011) que passaram a introduzir no mercado, através de tecnologias de fabricação, os fármacos sintéticos. Em contrapartida ao surgimento dessas indústrias e a síntese química para fabricação de medicamentos, o uso de plantas medicinais acabou perdendo espaço e foi, aos poucos, sendo substituído pela promessa de que os fármacos industrializados promovem efeitos mais rápidos e eficazes, atraindo as pessoas que buscavam a cura total.

Atualmente as plantas medicinais estão voltando a ganhar espaço, não sendo mais consideradas apenas como tratamento alternativo, favorecendo o aparecimento dos fitoterápicos. Essa mudança é reflexo do número crescente de pessoas que estão optando por um modo de vida mais natural (BRUNING et al., 2012). Bruning et al. (2012) também afirmam que esse aumento está associado na busca por terapias naturais, cuja ação é menos agressiva ao indivíduo e ao ambiente. Klein et al. (2009) sugerem que, além da preocupação com os efeitos colaterais do uso irracional dos medicamentos, o aumento no consumo de fitoterápicos ou plantas medicinais também pode estar vinculado aos custos elevados para a compra de fármacos sintéticos. É o que também consideram Mera et al. (2018) quando citam que a utilização de plantas medicinais, nativas ou cultivadas, pode diminuir os gastos com medicamentos industriais.

Apesar do crescente interesse pelas plantas medicinais, elas ainda são tratadas por muitas pessoas como crendices, com discriminação e descrédito quanto à sua eficácia e, o conhecimento sobre a utilização correta das mesmas ainda é insignificante, mesmo em situações em que os benefícios do uso estão comprovados cientificamente (MAGALHÃES-FRAGA; OLIVEIRA, 2010). Para os mesmos autores, tal situação demonstra a necessidade de o Brasil implantar ações que orientem a população quanto ao uso correto das plantas medicinais a fim de melhorar as condições de saúde e qualidade de vida de toda a população.

revista brasileira educação ambiental 
Nesse sentido, os autores reforçam que o ambiente escolar é um excelente aliado na implantação de projetos que promovam a educação da população para a utilização correta de plantas medicinais. Foi com o intuito de atender a esta necessidade que o Decreto № 5.813, de 22 de junho de 2006, instituiu a Política Nacional de Plantas Medicinais e Fitoterápicos.

A Política estabeleceu as diretrizes e as linhas prioritárias para 0 desenvolvimento de ações que garantam, dentre outros objetivos, o acesso seguro e o uso racional de plantas medicinais e fitoterápicos no país, o fortalecimento das cadeias e dos arranjos produtivos e o uso sustentável da biodiversidade brasileira (MINISTÉRIO DA SAÚDE, 2006). Para reforçar o atendimento das diretrizes, o Ministério de Educação (MEC) orienta as escolas a trabalharem o conhecimento tradicional onde também se inserem as plantas medicinais (BRASIL, 2009). Essas ações, aliadas com o processo de atualização do ensino de ciências, vinculando o conhecimento popular e o saber, promoverão o resgate e o fortalecimento do uso das plantas medicinais (SILVA, 2012).

Além disso, a promoção do conhecimento da biodiversidade nas escolas e o estímulo para a sua utilização com respeito, moderação e equilíbrio através de práticas de Educação Ambiental é uma alternativa para reverter o quadro de descrédito e discriminação das plantas medicinais (SILVA, 2012). A Educação Ambiental favorece a transmissão, para a sociedade, do saber sobre meio ambiente, biodiversidade e a importância da preservação, estimulando a formação da consciência ecológica (FERREIRA et al., 2016). Segundo Carvalho et al. (2011), mesmo que as gerações da atualidade possuam desinteresse pela temática ambiental, a adequada sensibilização pode favorecer o reconhecimento, por parte delas, quanto à necessidade e importância de preservar os saberes populares. Ao abordar a relevância do tema, associando com o cotidiano, com a saúde coletiva, a descoberta de medicamentos e ao tratamento fitoterápico de enfermidades tem-se a possibilidade de provocar os envolvidos para uma mudança de opinião e de postura em relação ao assunto. Com esse objetivo, o Ministério da Educação instrui as instituições de ensino a trabalhar temas distintos da grade curricular, no qual as plantas medicinais estão inseridas (BRASIL, 2006).

Segundo Kovalski et al. (2011), a escola deve ser um ambiente que proporcione o diálogo a respeito dos conhecimentos relacionados à cultura e do nosso dia-a-dia já que este favorece a análise dos saberes prévios dos alunos para então desenvolver conhecimentos mais elaborados. Levantar a necessidade do resgate e a importância do saber sobre plantas medicinais nas escolas pode incentivar o despertar da conscientização dos alunos sobre valorização da cultura da preservação ambiental, promovendo o aproveitamento sustentável da flora e a melhoria da qualidade de vida (CARVALHO et al., 2011).

Diante disso, o estudo teve como objetivos identificar o nível de conhecimento sobre plantas medicinais de estudantes do sétimo ano do Ensino Fundamental de duas escolas de diferentes municípios, uma particular com estudantes oriundos da zona urbana e outra pública cujos estudantes residem, em sua maioria, na zona rural; e avaliar a importância da realização de 
intervenções com atividades teórica e prática para favorecer o conhecimento sobre as mesmas, estimular o seu uso e ampliar o conhecimento sobre a biodiversidade.

\section{Material e método}

\section{Seleção das escolas}

A pesquisa foi desenvolvida em duas escolas, uma pública, denominada Escola A, e outra particular, denominada Escola B, localizadas em dois municípios próximos, inseridos na região da Depressão Central no Rio Grande do Sul (RS). Participaram do estudo alunos de turmas de sétimo ano do Ensino Fundamental, com faixa etária entre 12 e 14 anos. Com o intuito de padronizar o número de estudantes (26) das duas escolas, o estudo foi realizado com duas turmas de sétimo ano da Escola A e com uma turma da Escola B.

A Escola A, localizada em zona urbana, atende estudantes do Ensino Fundamental oriundos de todo o município e são, em sua maioria, filhos de agricultores. Formado basicamente por pequenas propriedades rurais, 0 município tem sua atividade econômica alicerçada na agropecuária. Já a Escola $B$ atende alunos de todos os níveis da Educação Básica e está situada na zona urbana, em um bairro periférico da cidade de um município maior em número de habitantes cuja economia está fundamentada na indústria e no comércio, tendo sua área rural extremamente reduzida em termos de área territorial. O bairro de localização da Escola B caracteriza-se como um "bairro dormitório", pois a maioria dos moradores reside no Bairro e se desloca diariamente para a região central da cidade para trabalhar.

\section{Nível de conhecimento e avaliação da eficiência de atividades práticas sobre plantas medicinais}

O método utilizado no estudo foi a pesquisa-ação, pois houve intervenção do pesquisador na formulação de estratégias de aprendizagem, com abordagem quali-quantitativa a partir da aplicação de dois questionários semiestruturados (Material suplementar 1 e 2) sobre plantas medicinais, um antes, identificado como Questionário 1, e outro após a intervenção, identificado como Questionário 2.

Cada aluno das escolas respondeu os questionários de forma individual, sendo o primeiro no mesmo dia da prática e o segundo, dois dias após, mediante assinatura, pelo responsável, do Termo de Consentimento Livre e Esclarecido. Não foi revelada a identidade dos alunos participantes e, desta forma, a pesquisa seguiu os padrões éticos estabelecidos para pesquisas qualitativas com pessoas.

Após a aplicação do questionário, foi realizada a intervenção constituída por uma parte teórica com apresentação de slides e atividade prática com plantas. A apresentação abordou conceitos e utilização em escala global de plantas medicinais, uma breve contextualização histórica, informações sobre as 
formas de uso, riscos e benefícios, importância da preservação e do uso de espécies nativas como medicinais. Durante a prática, plantas de diferentes espécies medicinais foram levadas e distribuídas aos alunos para observação de suas características (Maytenus ilicifolia Mart. ex Reissek (Espinheira-santa); Mikania glomerata Sprengl (Guaco); Schinus terebinthifolius raddi (Aroeiravermelha); Mentha spicata. L. (Hortelã); Plectranthus barbatus Andrews (Boldo); Aloe vera L. (Babosa); Cymbopogon citratus (DC.) (Cidreira); Achyrocline satureioides (Lam.) DC (Macela); Passiflora spp. (Maracujá)). Os estudantes puderam tocar, sentir o cheiro e observar a morfologia de cada planta, e assim, falar se conheciam a espécie ou não. Após foi realizado um debate que abordou usos, benefícios e malefícios das espécies apresentadas.

\section{Análise dos dados}

A análise dos questionários foi realizada a partir da leitura das respostas, seguida pela sua categorização e análise percentual das mesmas, sendo os dados de porcentagem tabulados e elaboradas tabelas e figuras no programa Microsoft Office Excel®.

\section{Resultados e discussão}

\section{Nível de conhecimento sobre plantas medicinais}

A análise das respostas em relação ao conhecimento prévio dos estudantes sobre plantas medicinais mostrou que, embora seja baixo o percentual, a maioria (54\%) dos estudantes da Escola A sabe o que são plantas medicinais. Esse número subiu para $92 \%$ após a intervenção (Figura $1 \mathrm{~A}$ ). 0 mesmo aconteceu na Escola $\mathrm{B}$, em que o número de alunos com conhecimento sobre plantas medicinais foi maior em relação à Escola $\mathrm{A}(68 \%)$ e aumentou após a realização da atividade prática (Figura 1B).

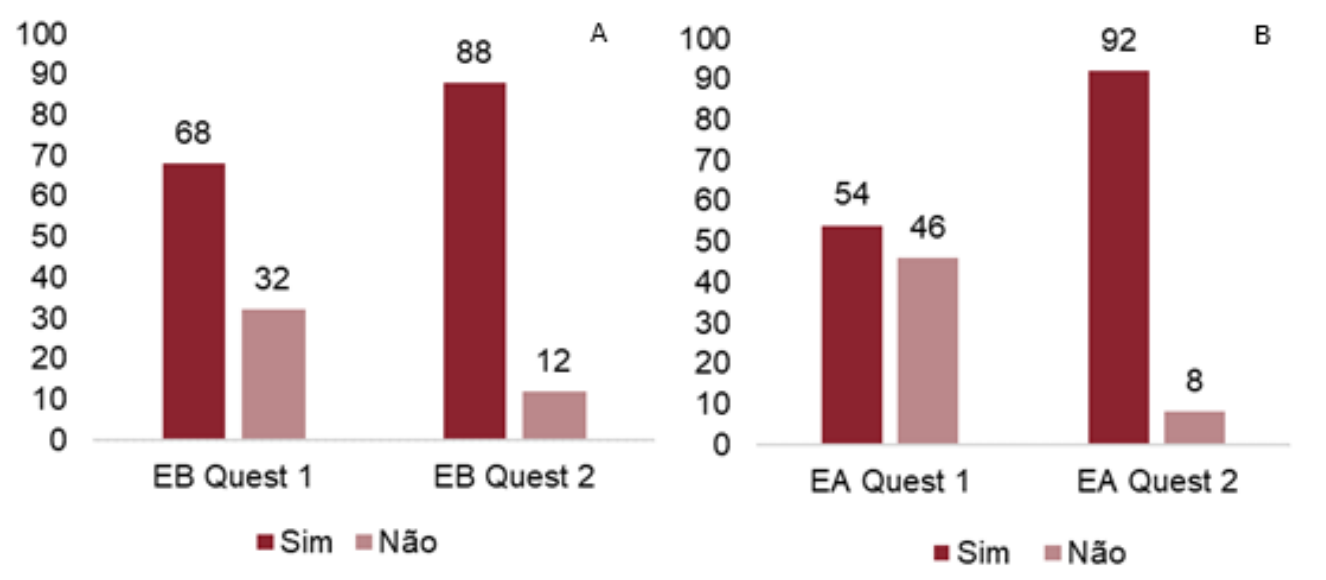

Figura 1: Nível de conhecimento sobre o conceito de plantas medicinais entre estudantes do sétimo ano do Ensino Fundamental de duas escolas (A e B) situadas na região da Depressão Central do Rio Grande do Sul, obtido a partir da aplicação de dois questionários, um antes (Questionário 1) e outro após (Questionário 2) a realização de uma intervenção com atividade prática. 
Em ambas as escolas houve redução do número de estudantes que disseram não ter conhecimento sobre plantas medicinais. Esses resultados mostraram que a intervenção constituída de atividades práticas contribuiu na aquisição de conhecimento sobre plantas medicinais.

Esses dados indicam a eficácia das aulas práticas no qual, além de simplificar a assimilação teórica e o mundo que os cerca, possibilita o diálogo e a construção de uma consciência científica (BARTZIK; ZANDER, 2016). Gonsalves et al. (2018) trabalharam com estudantes da $2^{\text {a }}$ série do Ensino Médio de uma escola da cidade de Patos, Paraíba, e avaliaram diferentes procedimentos de ensino e aprendizagem para a aquisição de conhecimentos botânicos e sobre a biodiversidade, utilizando plantas medicinais com aplicação de questionários antes e após a aplicação de uma atividade prática. Assim como no presente estudo, Gonsalves et al. (2018) constaram maior conhecimento em relação às espécies medicinais quando realizaram uma atividade prática. De acordo com Lima e Garcia (2011), aulas práticas têm o propósito de complementar as aulas teóricas, permitindo o contato e a visualização do objeto de estudo, favorecendo a aquisição do conhecimento.

A indicação de espécies medicinais conhecidas foi abordada nos dois questionários. Na Escola $\mathrm{A}$, os alunos citaram nove espécies no Questionário 1 , porém, estas receberam apenas 24 citações (Figura 2A), das quais nove foram citadas uma única vez. Com a intervenção, o número de espécies passou para 12 e o de citações para 65 (Figura 2B). Dentre as 12 espécies citadas no Questionário 2 da Escola $A$, nove foram usadas na parte prática da intervenção, comprovando que a oportunidade que tiveram de ver e tocar as plantas favoreceu a fixação do conteúdo. Além disso, no Questionário 1, duas plantas (babosa e camomila) tiveram o maior percentual de citações enquanto as demais foram citadas uma ou duas vezes. Já no Questionário 2, três plantas (babosa, macela e camomila) tiveram maior percentual de citações e apenas três foram citadas uma ou duas vezes. Outras quatro plantas citadas Questionário 1 não foram repetidas no Questionário 2.

$\mathrm{Na}$ escola $\mathrm{B}$, a diferença entre o número de plantas citadas nos questionários 1 e 2 foi muito pequena (Figuras $2 \mathrm{C}$ e 2D), porém o número de citações de plantas que conheciam passou de 59 para 103. Assim como ocorrido na Escola $A$, oito espécies usadas na parte prática da intervenção foram citadas no Questionário 2, dentre as quais cinco (babosa, hortelã, cidreira, guaco e macela) receberam o maior percentual de citações. Com relação ao aumento do número de citações de espécies, Gonsalves et al. (2018) também constataram maior número de espécies após a realização de atividades práticas. Além disso, os resultados são semelhantes aos do presente estudo em relação às espécies citadas como medicinais pelos alunos. Lopes et al. (2015), em levantamento de espécies medicinais utilizadas pela comunidade participante do programa Estratégia Saúde da Família de Pinheiros, em Maringá, Paraná, mostraram que as espécies mais citadas pelos participantes foram as mesmas espécies do presente estudo (babosa, camomila e macela). Já Souza e Felfili (2006), em levantamento etnobotânico

revista brasileira educação ambiental 
realizado com membros de uma comunidade do entorno do Parque Nacional da Chapada dos Veadeiros e da cidade de Alto Paraíso, Goiás, obtiveram resultados diferentes ao do presente estudo quando consideradas as espécies medicinais citadas. Percebe-se certa semelhança entre as espécies listadas nos dois estudos realizados na região sul do país e diferenças com as do estudo realizado na região centro-oeste do país. Essas diferenças podem ser explicadas pela diversidade botânica existente no Brasil e/ou pela diversidade de nomes populares usados para as espécies nas diferentes regiões do país.

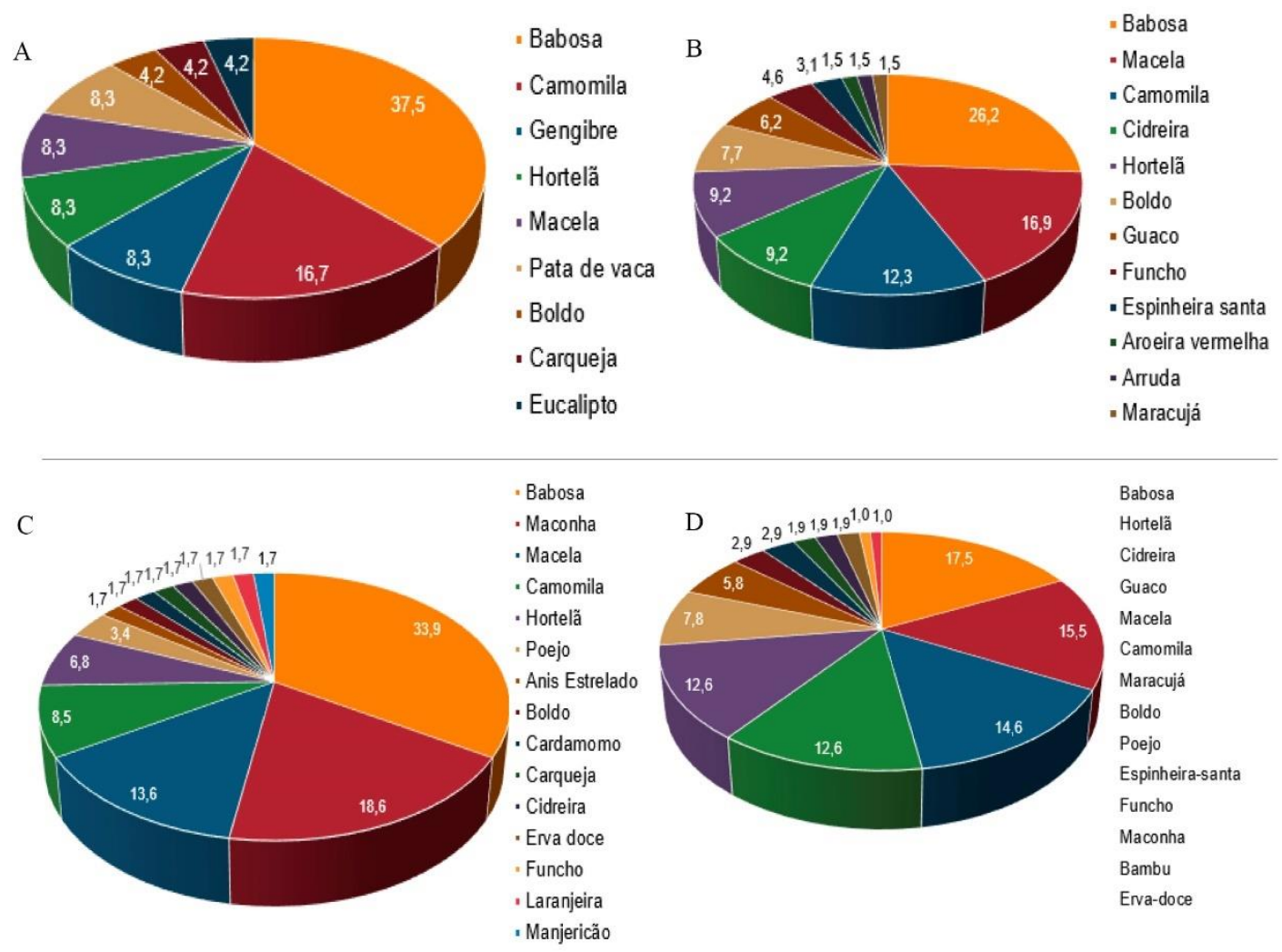

FIGURA 2: Plantas medicinais conhecidas e o respectivo percentual de citações em dois questionários aplicados para estudantes do sétimo ano do Ensino Fundamental de duas escolas da região da Depressão Central, Rio Grande do Sul, sendo um antes (Questionário 1) e outro após (Questionário 2) a realização de uma intervenção com atividade prática. 2A. Percentual de citações das espécies no Questionário 1 da Escola A; 2B. Percentual de citações das espécies no Questionário 2 da Escola A; 2C. Percentual de citações das espécies no Questionário 1 da Escola B; 2D. Percentual de citações das espécies no Questionário 2 da Escola B.

A citação da maconha por estudantes da Escola B (18,6 \% no Questionário 1), embora tenha ocorrido redução nesse número no Questionário $2(1,9 \%)$, serve de alerta à escola na averiguação das razões para tal 
indicação. A maconha, como planta medicinal, também foi citada no trabalho de Franco e Souza (2016) quando os autores verificaram o nível de conhecimento sobre plantas medicinais de alunos do EJA de duas escolas do município de Porto Velho, Rondônia. O estudo apenas traz a citação da mesma em sua lista de espécies medicinais descrita pelos participantes. Já no estudo de Souza (2013), que buscou identificar a percepção dos alunos de educação infantil e do ensino fundamental $\left(1^{\circ}\right.$ ao $5^{\circ}$ ano) sobre plantas medicinais, a maconha foi citada como planta medicinal apenas pelos estudantes do $4^{\circ}$ ano, pois haviam visto essa informação em um programa de televisão. Durante a atividade, Souza (2013) esclareceu aos alunos que a maconha é uma droga ilegal no país, e não é permitida a sua produção e comercialização em território nacional. No presente estudo, o maior número de citações da espécie pode ter sido em consequência de um dos estudantes ter questionado sobre a maconha ser ou não uma planta medicinal enquanto todos estavam respondendo o Questionário 1. Talvez a pergunta do colega tenha conduzido os demais a citar a espécie. Como resposta, foi explicado que a maconha está na lista de espécies medicinais, porém também é utilizada como uma droga ilícita, por possuir princípios ativos que causam efeitos alucinógenos. $E$ que, durante a produção de medicamentos são isolados outros compostos ativos que não causam efeitos alucinógenos. Acredita-se que o questionamento realizado pelo colega tenha estimulado outros colegas a citá-la. Mesmo assim, sugere-se que a Escola aborde o assunto em atividades que vierem a promover.

Outra espécie de destaque foi babosa por ter sido a mais citada nas duas escolas e nos quatro questionários. Ela também é citada por outros autores em listas de espécies medicinais conhecidas por diferentes comunidades (MOTTA et al., 2016; BATTISTI et al., 2013; LOPES et al., 2015). Porém, em nenhum dos estudos ela aparece como a mais citada pelos participantes. Provavelmente o elevado número de citações esteja relacionado com a importância regional dada à mesma.

Quando questionados sobre os usos (Questionário 1) das plantas medicinais que conhecem, os estudantes das duas escolas não conseguiram colocar respostas coerentes. No entanto, após a aplicação da atividade prática, os alunos fizeram várias citações de plantas, com seus respectivos tratamentos mostrando avanços na percepção da importância e do uso de plantas medicinais. No Questionário 2, os estudantes da Escola A mencionaram nove espécies (33 vezes para 19 diferentes usos) (Figura 3A). Já na Escola $B$ foram apresentadas 11 espécies (85 citações para 24 diferentes usos) (Figura 3B). As espécies mais citadas foram babosa, camomila, macela, boldo e hortelã, todas utilizadas na atividade prática.

Silva (2012), em estudo que objetivou identificar o nível de conhecimento de plantas medicinais de uma Escola municipal de Ensino Fundamental de Cachoeira do Sul, RS, com o intuito de usar os dados como ferramenta para a introdução da Educação Ambiental, entrevistou pais e alunos do sexto ano. $O$ autor registrou 62 plantas medicinais, dentre as quais, as mais citadas correspondem às mais citadas no presente estudo. Outro estudo, realizado por

revista brasileira educação ambiental 
Dluzniewski e Müller (2018), objetivou analisar os conhecimentos etnobotânicos sobre o uso de plantas medicinais na zona urbana e rural no município de Sete de Setembro, RS, registraram como as espécies mais citadas tanto na zona urbana como na zona rural, as mesmas plantas do presente estudo e do estudo realizado por Silva (2012) em Cachoeira do Sul. Os três estudos foram realizados em diferentes regiões do RS e sugerem que estas espécies são utilizadas por diferentes grupos do Estado e que, possivelmente, exista muita influência regional no uso das plantas medicinais.

É comum ocorrer o esquecimento sobre as propriedades terapêuticas das plantas medicinais, levando, muitas vezes, ao uso de uma espécie para uma determinada enfermidade quando o real efeito é sobre outra. Além disso, são seguidas orientações de conhecidos e a indicação da planta é feita, em geral, pelo nome popular. Isso pode levar ao seu uso incorreto, pois os nomes populares das plantas mudam muito de uma região para outra. Sendo assim, é importante que existam ações que promovam o conhecimento das ações terapêuticas das plantas medicinais e da sua identificação correta. De acordo com Veiga Jr. et al. (2005), os brasileiros costumam usar plantas que não possuem comprovação científica das propriedades terapêuticas. Além disso, essas espécies podem possuir efeitos contrários aos desejados, ocasionados pelo uso inadequado ou pelo uso da planta errada.

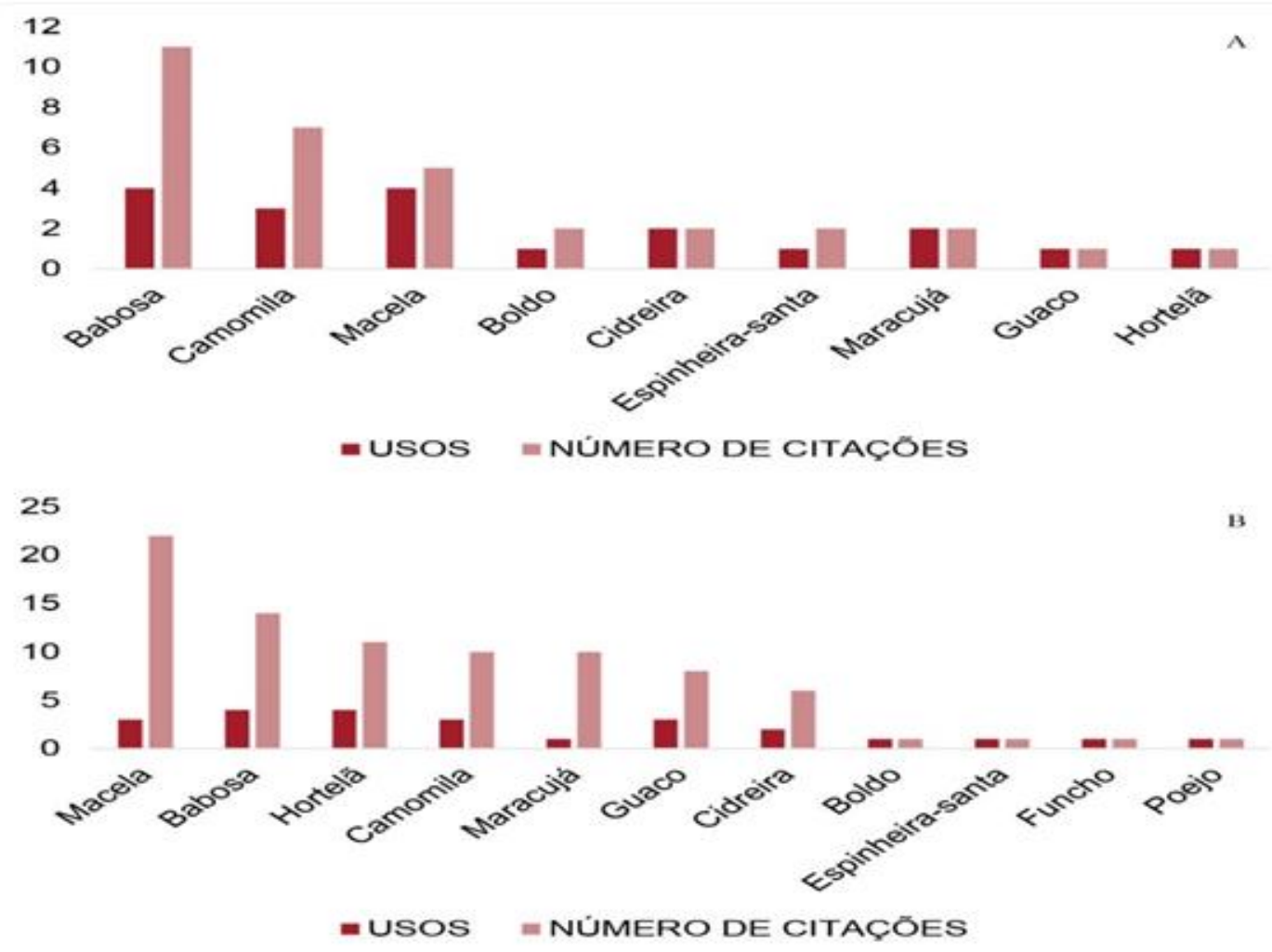

FIGURA 3: Espécies listadas por estudantes do sétimo ano de duas escolas de Ensino Fundamental da Depressão Central do Rio Grande do Sul, com a indicação de possíveis usos para cada uma e o número total de citações por espécie. 3A. Respostas dos estudantes da Escola A; 3B. Respostas dos estudantes da Escola B. 
Diante dessa realidade, os estudantes foram questionados quanto à possibilidade de as plantas medicinais causarem algum dano à saúde das pessoas. Em ambas as escolas foi possível perceber diferenças nas respostas entre os dois questionários. Na Escola $\mathrm{A}$, apenas $23 \%$ dos alunos afirmavam que $o$ uso de plantas medicinais poderia fazer mal. Porém, após a atividade prática, esse número mudou, passando para $84 \%$ dos alunos que passaram a considerar que o uso, quando inadequado, pode trazer riscos à saúde (Figura 4). Do mesmo modo, na Escola $B$ houve redução no número de estudantes que consideravam que o uso de espécies vegetais não poderia ocasionar danos à saúde.

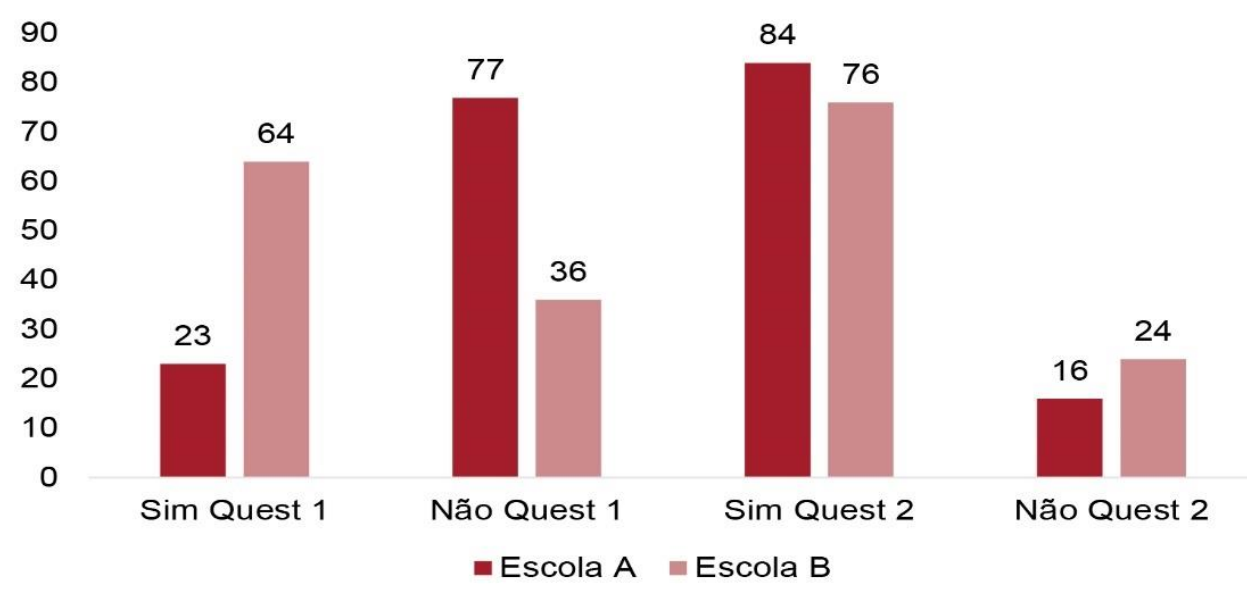

FIGURA 4: Percentual de estudantes do sétimo ano de duas escolas de Ensino Fundamental da região da Depressão Central, Rio Grande do Sul, que consideram a possibilidade de as plantas medicinais causarem algum dano à saúde das pessoas, antes (Questionário 1) e após (Questionário 2) a realização de uma intervenção com atividade prática.

A falta de conhecimento demonstrada pelos estudantes quanto aos riscos do uso inadequado e/ou desmoderado de plantas medicinais, considerando que, conforme citam França et al. (2008), a diferença entre a propriedade medicinal e a tóxica pode estar associada à quantidade ingerida do composto ativo, mostra a necessidade de ações para instruir os estudantes e a comunidade. Essa necessidade é reforçada por autores como MagalhãesFraga e Oliveira (2010) e é apoiada pela Política Nacional de Plantas Medicinais e Fitoterápicos (BRASIL, 2006) e pelo MEC que orientam as escolas a trabalharem o tema ao incluírem em seus currículos o resgate do conhecimento tradicional. Outro fator que mostra a importância da implantação de ações é o receio dos efeitos colaterais que podem ser causados pelo uso de medicamentos sintéticos e a crença que o uso de plantas medicinais, por serem naturais, não causem nenhum mal à saúde (VARELLA, 2010). Nesse sentido, o ambiente escolar constitui um excelente aliado para a implantação de projetos que promovam a educação da população para a utilização correta de plantas medicinais (MAGALHÃES-FRAGA; OLIVEIRA, 2010). 
$\mathrm{Na}$ sequência, ao finalizar a intervenção prática, os estudantes foram questionados quanto à continuidade do uso de plantas medicinais ou se passariam a utilizar. Na Escola $\mathrm{A}$, três alunos disseram que não iriam utilizar, já na Escola $B$ todos os alunos declararam que iriam utilizar. Entre as respostas mais relevantes do porquê continuariam ou passariam a utilizar estão: "Porque elas fazem bem e quando não queremos tomar remédios".; "Porque é melhor algo natural do que industrial".; "Porque não precisa gastar com remédios".

Do mesmo modo, quando questionados sobre o interesse em plantas medicinais com a prática realizada, como resultado, em ambas as escolas apenas quatro alunos disseram não possuir interesse. Entre as declarações citadas por eles estão "Porque é bom aprender sobre elas para podermos ensinar depois pra quem não sabe".; "Porque eu aprendi a usar essas plantas de maneira fácil".; "Porque adoro ciências, e eu acho que esse assunto deveria ser mais estudado". Essas respostas ressaltam o quanto a intervenção com atividade prática foi importante na formação pessoal de cada estudante. Partindo do interesse despertado nos estudantes, pode-se, associado com o tema plantas medicinais, desenvolver trabalhos de Educação Ambiental, contribuindo para a formação da consciência ecológica, sensibilizando os estudantes a darem importância para a preservação da biodiversidade (MERA et al., 2018).

Tanto no Questionário 1 como no 2, os estudantes foram questionados quanto ao desejo de ter uma horta com plantas medicinais na escola. Os estudantes demonstraram amplo interesse já no Questionário 1, não mudando significativamente os percentuais do 1 para o 2 nas duas escolas. Isso evidencia o interesse em implantar uma horta medicinal no âmbito escolar. Os alunos em suas respostas expressaram que, se tivesse uma horta medicinal na escola, eles teriam maior facilidade de acesso quando lhes fosse necessário. Mas também, podemos inferir que o interesse pela horta medicinal pode ser em consequência da vontade que possuem de realizar mais atividades fora da sala de aula o que também precisa ser considerado pelas escolas e professores.

Dispor de uma horta com plantas medicinais no espaço escolar é enriquecedor e estimula o saber consciente do estudante, além de ser um laboratório vivo em que, de forma interdisciplinar, podem ser realizadas pesquisas e atividades relacionadas à preservação ambiental (NEVES et al., 2010). Similarmente, Theisen et al. (2015) afirmam que uma horta proporciona a união entre teoria e prática, constituindo um importante material para a Educação Ambiental, em que podem ser realizadas diferentes atividades pedagógicas, principalmente com os anos iniciais do Ensino Fundamental, contribuindo no processo de ensino-aprendizagem do indivíduo.

Ao serem questionados sobre o conhecimento de espécies nativas medicinais, no Questionário 1 da Escola $A$ foram citadas apenas três espécies. Já na Escola B foram cinco. Ao considerar a mesma pergunta no Questionário 2, o número de espécies identificadas pelos alunos aumentou para 11 na Escola A, com 25 citações, e para 12, com 37 citações, na Escola B. Esse 
crescimento mostrou que os estudantes conseguiram aprender sobre novas espécies. No entanto, a maioria das plantas citadas em ambas as escolas no Questionário 2 foram exóticas. Isso evidenciou a necessidade de mais atividades práticas em razão da complexidade do tema e do excesso de conceitos e informações para um único momento prático. Além disso, nomes de espécies nativas e exóticas são complexos para serem assimilados, especialmente por não ser algo rotineiro para os estudantes. Também, evidencia o baixo conhecimento sobre a biodiversidade regional.

Estimava-se que os estudantes oriundos, em sua maioria, da zona rural (Escola A) tivessem mais conhecimento sobre plantas medicinais. Porém, em todas as questões os estudantes da Escola B, particular e localizada em zona urbana, demonstraram maior conhecimento sobre as plantas medicinais nos dois questionários. De forma inversa, Mera et al. (2018) constataram maior expressão do conhecimento sobre plantas medicinais por estudantes da escola rural quando comparado com os estudantes de uma escola urbana. Neste caso, os autores citaram como causa, o empoderamento do conhecimento tradicional que está, por sua vez, intimamente relacionado ao modo de vida próximo dos elementos naturais dos atores dessas comunidades. Já os resultados obtidos por Alves et al. (2017), que buscavam identificar o nível de conhecimento de alunos de duas escolas públicas da zona rural e urbana sobre o uso de plantas medicinais, corroboram com o registrado no presente estudo. Assim como no presente estudo, os estudantes da zona urbana demonstraram maior conhecimento sobre plantas medicinais. Um dos fatores que pode ter influenciado nos resultados do presente estudo é a perda, por parte dos estudantes da zona rural, dos conhecimentos passados de geração em geração, ou da necessidade desses estudantes de se apropriar de um modo de vida mais urbano, abrindo mão da sua cultura. Além disso, as famílias inseridas no meio urbano podem estar em busca de um modo de vida mais natural e estão passando isso aos filhos. Ou ainda, o maior conhecimento demonstrado por eles pode ter relação à facilidade de acesso à informação.

A realização da intervenção, composta por uma parte teórica e outra prática, contribuiu para a aprendizagem de conteúdos e para estimular o uso de espécies nativas medicinais, atribuindo ao aluno novas percepções sobre utilização da biodiversidade e sobre a necessidade da sua preservação. $O$ estudo também mostrou que a implantação do tema nas escolas pode favorecer a formação de cidadãos ecologicamente mais conscientes e contribuirá para que a Política Nacional de Plantas Medicinais e Fitoterápicos atenda suas diretrizes. 


\section{Referências}

ALMEIDA, M.Z. Plantas medicinais. $3^{\circ}$ ed, Salvador, EDUFBA, 2011. p. 221.

ALVES, M.H.; MEIRELES, M.P.A.; LEMOS, J.R. Percepção dos alunos de duas escolas do ensino básico sobre plantas medicinais, município de Buriti dos Lopes, norte do Piauí, Nordeste do Brasil. Revista Espacios, v. 38, n. 50, 2017.

BARTZIK, F.; ZANDER, L.D. A importância das aulas práticas de ciências no ensino fundamental. Revista Arquivo Brasileiro de Educação, Belo Horizonte, v.4, n. 8, 2016.

BATTISTI, C.; HORBACH, R.K.; GARLET, T.M.B. Espaços verdes medicinais em escolas públicas do município de Palmeira das Missões, RS. Revista Eletrônica em Gestão, Educação e Tecnologia Ambiental - REGET, v. 14, n. 14, p. 2823-2831. 2013.

BRASIL. Ministério da Saúde. Secretaria de Ciência, Tecnologia e Insumos Estratégicos. Departamento de Assistência Farmacêutica. Política Nacional de Plantas Medicinais e Fitoterápicos / Ministério da Saúde, Secretaria de Ciência, Tecnologia e Insumos Estratégicos, Departamento de Assistência Farmacêutica. Brasília: Ministério da Saúde, 2006.

BRASIL. Ministério da Saúde. Secretaria de Ciência, Tecnologia e Insumos Estratégicos. Departamento de Assistência Farmacêutica e Insumos Estratégicos. Programa Nacional de Plantas Medicinais e Fitoterápicos. Ministério da Saúde, Secretaria de Ciência, Tecnologia e Insumos Estratégicos, Departamento de Assistência Farmacêutica e Insumos Estratégicos. Brasília: Ministério da Saúde. 2009.

BRUNING, M.C.R.; MOSEGUI, G.B.G.; VIANNA, C.M.M. A utilização da fitoterapia e de plantas medicinais em unidades básicas de saúde nos municípios de Cascavel e Foz do Iguaçu. Paraná: a visão dos profissionais de saúde. Ciência \& Saúde Coletiva, v. 17, n. 10, 2012.

CARVALHO, O.C.; PINTO, G.A.; ARAÚJO, F.C.; TEIXEIRA, F.D. Estudo sobre a importância do resgate do saber popular sobre plantas medicinais e sua transmissão em escolas públicas de São João Del Rei - MG. Anais do VIII Encontro Nacional de Pesquisa em Educação em Ciências, 2011.

DLUZNIEWSKI, F.S.; MÜLLER, N.T.G., Estudo etnobotânico de plantas medicinais utilizadas no município de Sete de Setembro, Rio Grande Do Sul, Brasil. Perspectiva, Erechim, v. 42, n. 157, p. 49-61, 2018.

FERREIRA, T.P.; GONÇALVES, J.A.; ASSUNÇÃO, T.S. de, PANTOJA, S.C.S. A Educação Ambiental e o conhecimento de plantas medicinais para alunos do ensino fundamental na zona oeste, Realengo - RJ Anais do XIII Congresso Nacional de Meio Ambiente de Poços de Caldas, 2016. Disponível em: <www.meiomabientepocos.com.br>. Acesso em: 10 jun. 2019. 
FRANCO, S.E.P.; SOUZA, A.C.R. Levantamento das plantas medicinais utilizadas por alunos do programa de ensino de jovens e adultos (EJA) no município de Porto Velho - RO. Saber Científico, Porto Velho. 2016.

FRANÇA, I.S.X.; SOUZA, J.A.; BAPTISTA, R.S; BRITTO, V.R.S. Medicina popular: benefícios e malefícios das plantas medicinais. Revista Brasileira de Enfermagem, Brasília, 2008.

GONSALVES, F.N., FARIAS, A.B., QUEIROZ, R. O estudo de plantas medicinais na melhoria da aprendizagem dos conteúdos de botânica no ensino médio. Anais do V Congresso Nacional de Educação, v.1, 2018.

KLEIN, T.; LONGHINI, R.; BRUSCHI, M.L.; MELLO, J.C.P. Fitoterápicos: um mercado promissor. Revista Ciência Farmacêuticas Básica e Aplicada. 30 (3):241-248, 2009.

KOVALSKI, M.L.; OBARA, A.T. Plantas medicinais na escola Victor Beloti: O diálogo entre o saber popular e o conhecimento científico. Maringá Ensina, $v$. 20, p. 26-29, 2011.

LIMA, D.B.; GARCIA, R.N. Uma investigação sobre a importância das aulas práticas de Biologia no Ensino Médio. Cadernos do Aplicação, Porto Alegre, v. 24, n. 1, 2011.

LOPES, M.A.; NOGUEIRA, I.S.; OBICI, S.; ALBIERO, A.L.M. Estudo das plantas medicinais, utilizadas pelos pacientes atendidos no programa "Estratégia saúde da família" em Maringá/PR/Brasil. Revista Brasileira de Plantas Medicinais. Campinas - SP, v. 17, n. 4, p. 702-706, 2015.

MAGALHÃES-FRAGA, S.A.P.; OLIVEIRA, M.F.S. Fito-partner Schools: Health, Environment and Education by Managing Medicinal Plants. Revista Fitos, v. 5, n. 1, p. 46-58, 2010

MERA, J.C.E.; ROSAS, L.V.; LIMA, R.A.; PANTOJA, T.M.A. Conhecimento, Percepção e Ensino Sobre Plantas Medicinais em Duas Escolhas Públicas no Município de Benjamin Constant - AM. Experiências em Ensino de Ciências, v.13, n. 2, 2018.

MONTEIRO, S.C.; BRANDELLI, C.L.C. Farmacobotânica: Aspectos Teóricos e Aplicação. Porto Alegre - Artmed, 2017.

MOTTA, A.O.; LIMA, D.C.S., VALE, C.R. Levantamento do uso de plantas medicinais em um centro de educação infantil em Goiânia - GO. Revista da Universidade Vale do Rio Verde, Três Corações, v. 14, n. 1, p. 629, 2016.

NEVES, J.D.S.; BARROS, G.F.X.; BARROS, G. F. X. Experiência de Gestão e Educação Ambiental no projeto Farmácia Viva em duas Escolas. In: 1o SIMAGA - Simpósio Alagoano de Gestão Ambiental, Arapiraca - AL, Brasil, UNEAL/CAMPUS I, p. 21-30, 2010.

SILVA, M.R. da. A utilização do conhecimento de plantas medicinais como ferramenta para estimular a preservação ambiental. Monografias ambientais, v. 6, n. 6, p. 1354-1380, 2012.

revista brasileira educação ambiental 
SOUSA, B.M.N.C. Percepção de crianças sobre plantas medicinais em ambiente escolar de educação infantil e ensino fundamental em Florianópolis, SC. 2013. Trabalho de Conclusão de Curso (Curso de Agronomia, Centro de Ciências Agrárias) - Universidade Federal de Santa Catarina.

SOUZA, C.D.; FELFILI, J.M. Uso de plantas medicinais na região de Alto Paraíso de Goiás, GO, Brasil. Revista Acta Botanica Brasilica. 20(1): 135142, 2006.

THEISEN, G.R.; BORGES, G.M.; VIEIRA, M.F.; KONFLANZ, T.L.; NEIS, F.A.; SIQUEIRA, A.B. Implantação de uma horta medicinal e condimentar para uso da comunidade escolar. Revista Eletrônica em Gestão, Educação e Tecnologia Ambiental, v. 19, n. 1, p.167-171, 2015.

VARELLA, D. Ervas medicinais: os conselhos de Drauzio Varella. [entrevista disponibilizada em 13 de agosto de 2010]. Entrevistadora: Cristiane Segatto. Porto Alegre: Revista Época. Ed. Globo, 2010. Disponível em: $<$ http://revistaepoca.globo.com/Revista/Epoca/0,EMl162899-15230,00-\%20 ERVAS\%20MEDICINAIS\%20OS\%20CONSELHOS\%20DE\%20DRAUZIO\%20 VARELLA.html> Acesso em: 18 jun. 2019.

VEIGA, V.F.Jr.; PINTO, A.C.; MACIEL, M.A.M. Plantas medicinais: cura segura? Revista Química Nova, Vol. 28, No. 3, 519-528, 2005.

WONGTSCHOWSKI, P. Indústria química: riscos e oportunidades. São Paulo: Blucher, $2^{\circ}$ ed, 2011. 